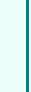

\title{
Trimming of a Migrated Biliary Nitinol Stent Using Argon Plasma
}

\author{
Hiroyuki Matsubayashi Noriaki Hasuike Masaki Tanaka \\ Kohei Takizawa Yuichiro Yamaguchi Hiroyuki Ono \\ Division of Endoscopy, Shizuoka Cancer Center, Shizuoka, Japan
}

\section{Key Words}

Metallic stent $\cdot$ Migration $\cdot$ Bile duct $\cdot$ Argon plasma $\cdot$ Trimming

\begin{abstract}
Metallic stent migration is a well-known complication which cannot always be managed by removal or repositioning, especially in case of uncovered stent. We report a patient who developed obstructive jaundice due to migration of an expandable metallic stent (EMS) inserted in the lower bile duct. Trimming of the EMS using argon plasma was performed, with the power setting of $60 \mathrm{~W}$ and $2.0 \mathrm{l} / \mathrm{min}$ of argon flow. The distal part of the EMS was removed and mechanical cleaning using balloon catheter was performed for remnant EMS. Without additional stent insertion, jaundice was relieved in a few days. No complication was recognized during the procedure and no recurrence of jaundice in the rest of his life.
\end{abstract}

\section{Background}

Nowadays, insertion of an expandable metallic stent (EMS) is the standard treatment to rescue obstructive jaundice caused by unresectable pancreaticobiliary malignancies. As one of the problematic complications of biliary EMS, stent migration occurs in 1.8-8.3\% of cases with covered biliary EMS and in $0-2.4 \%$ of uncovered EMS [1-3]. Migration of biliary EMS may cause severe complications such as ulceration [4], perforation [5] and intestinal obstruction [6], so that appropriate treatments are needed. Several techniques have been reported on endoscopic removal of biliary EMS [7-9] and the success rate of removal was $86.4-92.3 \%[10,11]$ in cases of covered EMS. However, it is still difficult in cases of uncovered EMS (0-38.4\%) [10,11]. Stent trimming is another approach to treat EMS migration [4]. To date, YAG laser [4, 12] and argon plasma [13-15] have been applied to transect metallic stents. We herein report a case of advanced pancreatic cancer with occurrence of obstructive jaundice due to migration and occlusion of a self-expandable biliary nitinol stent. 


\section{Case Report}

In April 2007, an 84-year-old man developed jaundice and was admitted to hospital. By several image examinations and blood test he was diagnosed as suffering from advanced pancreatic cancer invading to portal vein. He refused aggressive therapies such as surgical operation and chemotherapy because of insufficient physical condition and high age. To rescue obstructive jaundice, after temporary nasobiliary drainage, an uncovered EMS (Niti-S biliary stent, $10 \mathrm{~mm} \times 6 \mathrm{~cm}$ ) was inserted in the lower bile duct in June 2007. During best supportive care, he developed icterus and was referred to our institute in July 2008. On admission, laboratory data showed bilirubinemia (total bilirubin: $3.0 \mathrm{mg} / \mathrm{dl}$ ), a high level of hepatobiliary enzyme (GOT: $129 \mathrm{U} / \mathrm{l}$, GPT: $78 \mathrm{U} / \mathrm{l}, \gamma \mathrm{GTP}: 574 \mathrm{U} / \mathrm{l}$ ) and inflammatory reaction (CRP: $3.11 \mathrm{mg} / \mathrm{dl}$ ). A duodenoscope (Olympus, JF-260V) was inserted to examine biliary obstruction. At the duodenal papilla, the biliary EMS was migrated toward the anal side of the duodenal lumen about $2 \mathrm{~cm}$ in length (fig. 1). The stent was not covered and it seemed difficult to remove by grasping or snaring stent $[10,11]$ despite a couple of attempts. The endoscope was changed into the upper gastrointestinal scope (Olympus, GF-H260) with hood attachment at the top and was inserted again. Trimming of the EMS was performed using argon plasma, a few millimeters from the papilla's orifice, in order not to cause ulceration or oozing from the duodenal mucosa (fig. 2). The power setting of argon plasma was $60 \mathrm{~W}$ and $2.0 \mathrm{l} / \mathrm{min}$. Transection of the stent was done from the oral to the anal side. Air vacuuming was frequently done to reduce inspired gas in the duodenum. In about $30 \mathrm{~min}$, the EMS was completely cut off and the distal side of the stent was removed. By mechanical cleaning using

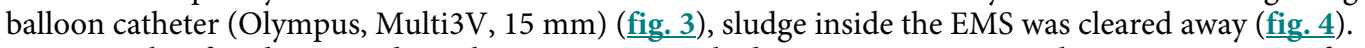
Four months after this procedure, the patient succumbed to severe pneumonia, but no recurrence of jaundice was noted after the procedure of EMS trimming.

\section{Discussion}

The incidence of biliary EMS migration is not really high (0-8.3\%) and it is less frequent in cases of uncovered EMS [1-3]. Endoscopic removal is successful in most cases of covered EMS (success rate: $86.4 \%$ [11] to $92.3 \%$ [10]), but it is difficult in uncovered ones $(0 \%$ [11] to $38.4 \%$ [10]). Several methods have been developed to efficiently improve the removal of EMS without complication, such as the 'lasso technique' [8], the 'wire-loop technique' [7], or the 'open-biopsy-forceps technique' [9] using foreign-body forceps and polypectomy snares $[10,11]$. Kahaleh et al. described that removal of uncovered EMS was difficult and required a combination of techniques in addition to the devices previously described [16]. Surgery is another choice of treatment for patients with failed endoscopic removal. However, when the inserted EMS was migrated, most patients with pancreaticobiliary malignancies were thought to be in advanced stage, hence a less invasive approach is needed for the management of biliary drainage. Therefore, a less invasive, easy method is wanted to rescue EMS migration.

Recently, Demarquay et al. demonstrated the efficacy of argon plasma for endoscopic shortening of biliary wallstent [13] and they also succeeded in trimming other types of EMS, including esophageal and colorectal stents [14]. According to the report mostly done on Wallstent with largest the series (31 cases) [14], recommended power setting was $70-80 \mathrm{~W}$ with argon flow of $0.8 \mathrm{l} / \mathrm{min}$, however it was quite similar to ours according to the second largest study ( 6 cases) done on nitinol stent ( $60 \mathrm{~W}, 1.8 \mathrm{l} / \mathrm{min}$ ) [15]. By an in vitro experimental model, it is reported that at least $60 \mathrm{~W}$ of argon plasma was required to cut the bare metallic stent, with a different effect level by duration of irradiation and stent condition (wet or dry) [17]. We should be careful on the type of stent metal, because melting temperature is different between nitinol alloy (Niti-S stent) and stainless steel (Wallstent) $[15,18]$. As the temperature generated by argon plasma is between 1,000 and $1,300^{\circ} \mathrm{C}$ and the melting point of nitinol (alloy of nickel and titanium) is around 1,200$1300^{\circ} \mathrm{C}$, nitinol stents can be easily cut [15]. While trimming EMS, we must be aware that the stent is well washed out and there is no sludge on the surface so that heat energy conducts well. Too much burst causes injury of the bile duct epithelium [19]. 
In our case, transection of the biliary metallic stent was performed with argon plasma in acceptable time without complication. Today the argon plasma device is widely used in hospitals around the world. We suggest that argon plasma trimming is a less expensive, safe and effective method to rescue migrated uncovered biliary metallic stents.

Fig. 1. The uncovered metallic stent was migrated from the duodenal papilla and was occluded by sludge.

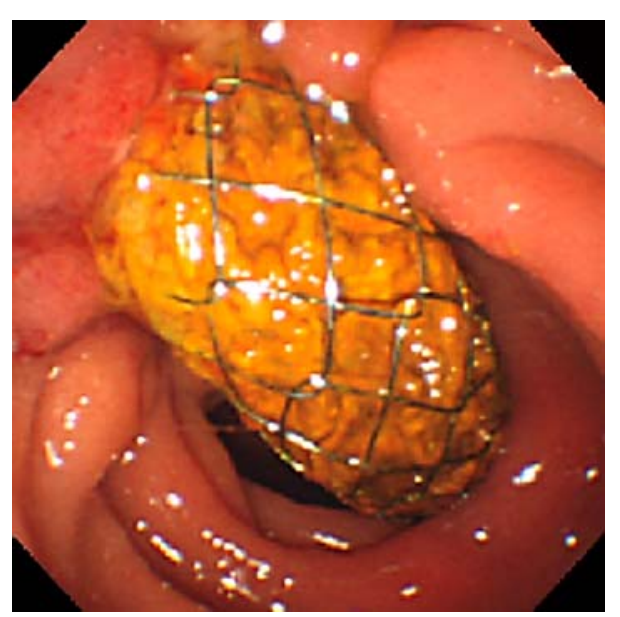

Fig. 2. Argon plasma was applied to transect the distal side of the migrated metallic stent near the papilla. A hood was attached in order not to injure the gastrointestinal lumen when removing the detached metallic stent.

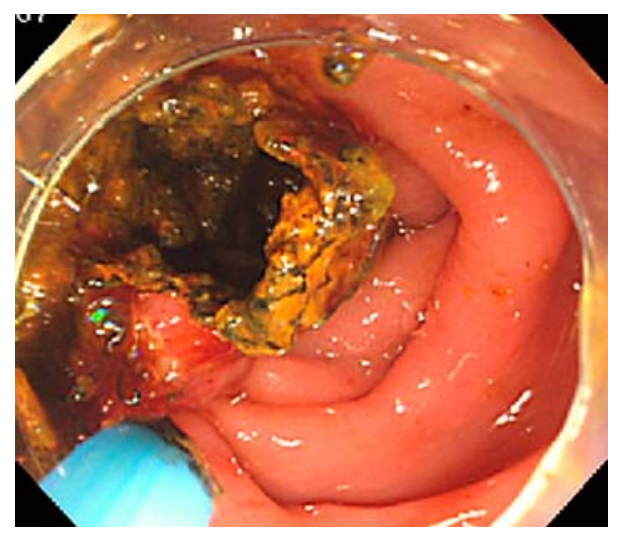




\begin{tabular}{r|l|l|l} 
Case Reports in & $\begin{array}{l}\text { Case Rep Gastroenterol 2009;3:202-206 } \\
\text { D0I: 10.1159/000226252 }\end{array}$ & Published online: July 31, 2009 & $\begin{array}{l}\text { O 2009 S. Karger AG, Basel } \\
\text { ISSN 1662-0631 } \\
\text { www.karger.com/crg }\end{array}$ \\
\hline
\end{tabular}

Fig. 3. Using balloon catheter, mechanical cleaning was performed to clear away sludge inside the metallic stent.

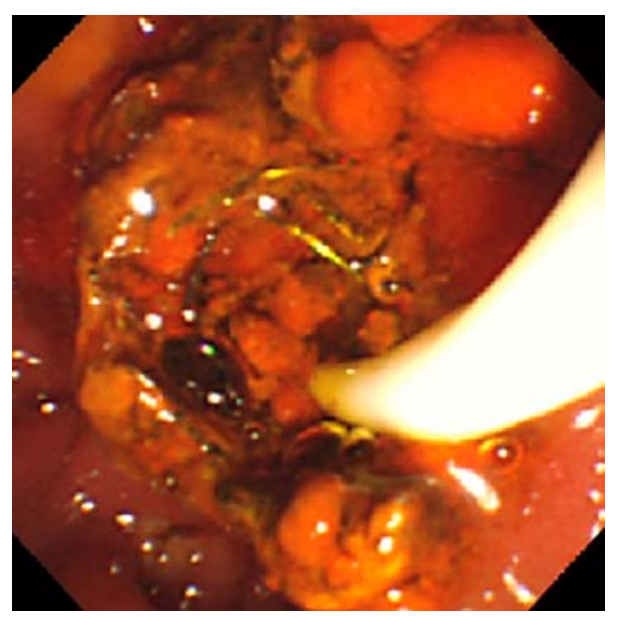

Fig. 4. A After trimming and sludge cleaning, the inside of the stent became wide open. B Endoscopic retrograde cholangiography using balloon catheter showed sufficient width of the biliary duct and good flow of contrast medium.
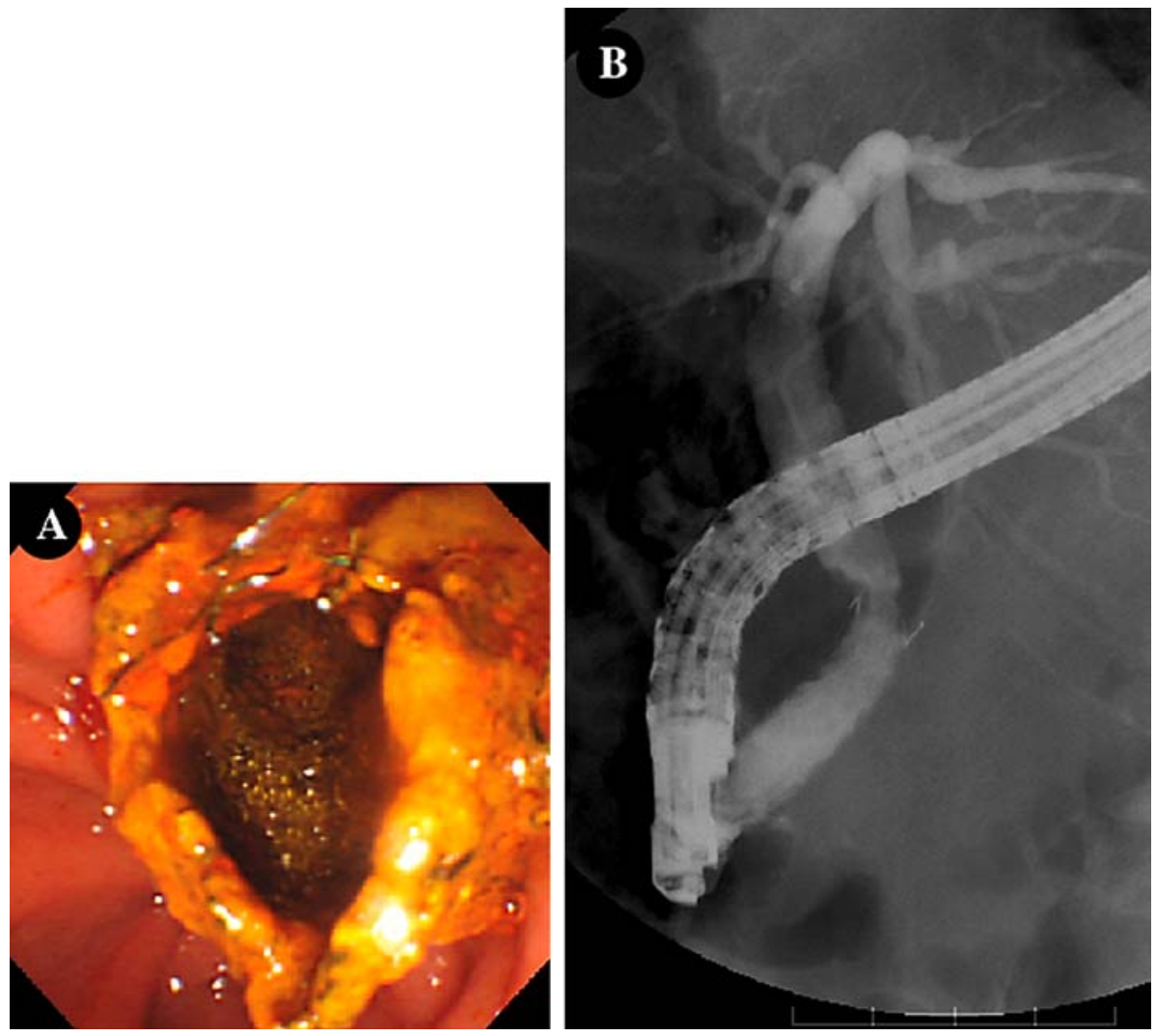


\section{References}

-1 Yoon WJ, Lee JK, Lee KH, Lee WJ, Ryu JK, Kim YT, Yoon YB: A comparison of covered and uncovered Wallstents for the management of distal malignant biliary obstruction. Gastrointest Endosc 2006;63:996-1000.

-2 Isayama H, Komatsu Y, Tsujino T, Sasahira N, Hirano K, Toda N, Nakai Y, Yamamoto N, Tada M, Yoshida H, Shiratori Y, Kawabe T, Omata M: A prospective randomised study of 'covered' versus 'uncovered' diamond stents for the management of distal malignant biliary obstruction. Gut 2004;53:729-734.

- 3 Park do H, Kim MH, Choi JS, Lee SS, Seo DW, Kim JH, Han J, Kim JC, Choi EK, Lee SK: Covered versus uncovered wallstent for malignant extrahepatic biliary obstruction: a cohort comparative analysis. Clin Gastroenterol Hepatol 2006;4:790-796.

-4 Yarze JC, Poulos AM, Fritz HP, Herlihy KJ: Treatment of metallic biliary stent-induced duodenal ulceration using endoscopic laser therapy. Dig Dis Sci 1997;42:6-9.

5 Thumbe VK, Houghton AD, Smith MS: Duodenal perforation by a Wallstent. Endoscopy 2000;32:495-497.

6 Ikeda T, Nagata S, Ohgaki K: Intestinal obstruction because of a migrated metallic biliary stent. Gastrointest Endosc 2004;60:988-989.

7 Amann ST, Somogyi L: A wire-loop technique for removal of migrated and embedded biliary stents. Gastrointest Endosc 2000;51:485-486.

-8 Mergener K, Baillie J: Retrieval of distally migrated, impacted biliary endoprostheses using a novel guidewire/basket 'lasso' technique. Gastrointest Endosc 1999;50:93-95.

\9 Matsushita M, Takakuwa H, Nishio A, Kido M, Shimeno N: Open-biopsy-forceps technique for endoscopic removal of distally migrated and impacted biliary metallic stents. Gastrointest Endosc 2003;58:924-927.

-10 Familiari P, Bulajic M, Mutignani M, Lee LS, Spera G, Spada C, Tringali A, Costamagna G: Endoscopic removal of malfunctioning biliary self-expandable metallic stents. Gastrointest Endosc 2005;62:903-910.

11 Shin HP, Kim MH, Jung SW, Kim JC, Choi EK, Han J, Lee SS, Seo DW, Lee SK: Endoscopic removal of biliary self-expandable metallic stents: a prospective study. Endoscopy 2006;38:1250-1255.

12 Zuber-Jerger I, Kullmann F: Trimming of a broken migrated biliary metal stent with the Nd:YAG laser. Case Rep Gastroenterol 2009;3:16-20.

$\checkmark 13$ Demarquay JF, Dumas R, Peten EP, Rampal P: Argon plasma endoscopic section of biliary metallic prostheses. Endoscopy 2001;33:289-290.

14 Vanbiervliet G, Piche T, Caroli-Bosc FX, Dumas R, Peten EP, Huet PM, Tran A, Demarquay JF: Endoscopic argon plasma trimming of biliary and gastrointestinal metallic stents. Endoscopy 2005;37:434-438.

15 Christiaens P, Decock S, Buchel O, Bulte K, Moons V, D’Haens G, Van Olmen G: Endoscopic trimming of metallic stents with the use of argon plasma. Gastrointest Endosc 2008;67:369-371.

-16 Kahaleh M, Tokar J, Le T, Yeaton P: Removal of self-expandable metallic Wallstents. Gastrointest Endosc 2004;60:640-644.

17 Tai M, Ichii O, Watanabe T, Ejiri Y, Otsuki M: Transection of metal stents using argon plasma coagulation. Dig Endosc 2008;20:29-32.

18 Maetani I, Ukika T, Inoue H, Igarashi Y, Sakai Y: Microwave recanalization: thermal effects with nitinol and stainless-steel stents. Endoscopy 2001;33:533536.

19 Chen YK, Jakribettuu V, Springer EW, Shah RJ, Penberthy J, Nash SR: Safety and efficacy of argon plasma coagulation trimming of malpositioned and migrated biliary metal stents: a controlled study in the porcine model. Am J Gastroenterol 2006;101:2025-2030. 